\title{
Novel Synthesis of Mesoporous Hydroxyapatite using Carbon Nanorods as a Hard-Template
}

Joanna Kamieniak, Aidan M. Doyle*, Peter J. Kelly and Craig E. Banks*

Faculty of Science and Engineering,

Manchester Metropolitan University, Chester Street, Manchester M1 5GD, UK

Submission to: Ceramics International

*To whom correspondence should be addressed.

Email: a.m.doyle@mmu.ac.uk and c.banks@mmu.ac.uk; Tel: ++(0)1612471196

Website: www.craigbanksresearch.com 


\begin{abstract}
A novel hard-template synthesis approach for the fabrication of mesoporous hydroxyapatite (HAP) is described herein. Carbon nanorods, synthesised using mesoporous silica (SBA-15) and an acidified sucrose solution, are used as a hard template, after which, they are utilised to synthesise mesoporous HAP. Transmission electron microscopy (TEM), X-ray diffraction (XRD) energy-dispersive X-ray spectroscopy (EDX) and nitrogen adsorption/BrunauerEmmett-Teller (BET), are all employed to characterise the synthesised materials. We demonstrate that this approach allows for the successful fabrication of single phase HAP with surface area $242.20 \pm 2.27 \mathrm{~m}^{2} \mathrm{~g}^{-1}$ and average pore diameter $3.5 \mathrm{~nm}$ and $18.9 \mathrm{~nm}$. This work proposes for the first time a bespoke innovative procedure that employs carbon nanorods as a template for the synthesis of mesoporous HAP via a hard templating protocol.
\end{abstract}




\section{Introduction}

Hydroxyapatite (HAP), $\mathrm{Ca}_{10}\left(\mathrm{PO}_{4}\right)_{6}(\mathrm{OH})_{2}$, is an inorganic compound with an elemental composition similar to that found in teeth and bones, and has been extensively used as a substitute material in dental and orthopaedic medical fields.[1] HAP possesses a characteristic hexagonal structure of $\mathrm{PO}_{4}$ tetrahedrons, with the $\mathrm{P} 6_{3} / \mathrm{m}$ space group, whereby chargebalancing $\mathrm{Ca}^{2+}$ and $\mathrm{OH}^{-}$ions reside on the c-axis.[2] Their high structural stability, bifunctionality of acidic and basic sites and the possibility of isomorphous substitution makes HAP an excellent catalyst support, as summarised in a recent review.[3] Its hydrophilic properties allow it to be used directly as a heterogeneous catalyst in dehydration reactions, e.g. the reaction of lactic acid to produce acrylic acid, an important intermediate for acrylate polymers and other key molecules[4, 5] or in the Guerbet coupling of alcohols.[6-8] The addition of metals, either as nanoparticles and/or substituted into the framework, greatly increases the range of reported reactions including acetone condensation[9], water-gas shift[10], alkane dehydrogenation/oxidative coupling[11-14], alcohol synthesis/transformation[15] or oxidation of volatile organic compounds[16-18], alcohol[19, 20], carbon monoxide[21] and methane[22-24]. For example, Yoon and co-workers studied the effects of adding ceria to Ni/HAP catalysts with a view to reducing the well-established tendency for Ni to generate carbon during reactions. Results showed that ceria doped samples enhanced the catalytic stability, due to the oxygen storage capacity of ceria preventing excessive carbon deposition.[25] In addition to the catalytic and environmental applications of HAP, the most explored and described area of application of HAP is biomedicine, due to its biocompatibility and extreme similarity to human bones.

There is a plethora of examples of HAP described in the literature that mostly involves replacement of damaged parts of musculoskeletal systems, but also plays a crucial role in drug or gene delivery agents using substituted HAP, all summarised in the review written by Supova et.al. and published in Ceramics International.[26] In fact, although it has been described that ingrowth of HAP in human bones increases with the porosity of HAP, at the same time the degradation rate of HAP also increases, limiting HAPs vitro reactivity. However such problems have been overcome with substituted HAP, making it a perfect biomaterial.[27, 28] For instance, Wiesmann and co-workers described HAP substituted with potassium that was later involved in the process of dentin mineralisation.[29] Other than potassium, zinc can be found in all biological tissues and plays vital role in different biological functions, yet deficiency of this mineral is associated with decreased bone density, thus $\mathrm{Zn}$ substituted HAP has been extensively investigated to promote osteoblast activity.[30] 
In this paper, we report for the first time, the successful novel preparation methodology of mesoporous HAP using a hard templating approach, employing carbon nanorods as a template. All synthesised materials have been analysed for characteristic features in morphology, crystallinity and porosity of the products. 


\section{Experimental}

\subsection{Materials and chemicals}

All chemicals were obtained from Sigma-Aldrich and were used as received without any further purification. All solutions were made by using deionised water with a resistivity not less than $18.2 \mathrm{M} \Omega \mathrm{cm}$.

\subsection{Carbon nanorod synthesis}

Mesoporous silica SBA-15 silica was prepared by dissolving Pluronic P123 (structuredirecting agent, $6 \mathrm{~g})$ into a solution of deionized water $(45 \mathrm{~mL})$ and $\mathrm{HCl}(180 \mathrm{~g}, 2 \mathrm{M})$, followed by stirring at $35-40{ }^{\circ} \mathrm{C}$ for $20 \mathrm{~min}$. TEOS (silica source, $12.8 \mathrm{~g}$ ) was added and the solution was stirred continuously for a further 20 hours. The entire contents were then transferred into a PTFE bottle and the mixture was aged for a further $24 \mathrm{~h}$ at $90{ }^{\circ} \mathrm{C}$ under static conditions. The resulting white powder was obtained by filtration and purified via washing with ethanol and deionized water. The product was calcined at $550{ }^{\circ} \mathrm{C}$ for 12 hours using a heating ramp rate of $2{ }^{\circ} \mathrm{C} \mathrm{min}^{-1}$. The calcined silica template $(1 \mathrm{~g})$ was impregnated with an aqueous solution containing sucrose $(1.25 \mathrm{~g})$, concentrated $\mathrm{H}_{2} \mathrm{SO}_{4}(78.87 \mu \mathrm{L})$ and deionised water $(5 \mathrm{~mL})$. The mixture was placed in the drying oven for 6 hours at $100{ }^{\circ} \mathrm{C}$ and a further 6 hours at $160{ }^{\circ} \mathrm{C}$. The sample turned dark brown and contained partially carbonised sucrose, which was impregnated again with the solution of sucrose $(0.8 \mathrm{~g})$, concentrated $\mathrm{H}_{2} \mathrm{SO}_{4}(50.7 \mu \mathrm{L})$ and deionised water $(5 \mathrm{~mL})$ and dried in the oven in the same manner as before, increasing the temperature after 6 hours from $100^{\circ} \mathrm{C}$ to $160^{\circ} \mathrm{C}$. The carbonisation was completed by pyrolysis under a flow of helium $\left(50 \mathrm{~mL} \mathrm{~min}^{-1}\right)$ at $800{ }^{\circ} \mathrm{C}$. The obtained powder was washed twice with $\mathrm{NaOH}$ (50:50 ethanol:water) at $100{ }^{\circ} \mathrm{C}$ to remove the silica template, then filtered and dried at $120^{\circ} \mathrm{C}$.

\subsection{HAP synthesis}

Carbon nanorods $(0.3 \mathrm{~g})$ were suspended in deionised water $(6 \mathrm{~mL})$ using an ultrasonic bath and added to a solution of $\left(\mathrm{NH}_{4}\right)_{2} \mathrm{HPO}_{4}(0.4 \mathrm{M}, 100 \mathrm{~mL})$, which was stirred at room temperature $\left(18-22{ }^{\circ} \mathrm{C}\right)$ in a $2 \mathrm{~L}$ beaker, with $\mathrm{Ca}\left(\mathrm{NO}_{3}\right)_{2}(0.6 \mathrm{M}, 100 \mathrm{~mL})$ added dropwise over one hour, resulting in a 'milky' suspension of HAP. The $\mathrm{Ca} / \mathrm{P}$ molar ratio was kept at 1.67 , corresponding to the stoichiometry of HAP. The $\mathrm{pH}$ was maintained through the addition of $\mathrm{NaOH}(0.1 \mathrm{M})$ within the range 9.4-9.5. This 'milky' suspension was then stirred overnight at room temperature using a magnetic stirring bar. The obtained precipitate was filtered, cleaned 
alternately with water and ethanol three times, oven dried at $65{ }^{\circ} \mathrm{C}$ for six hours, and then calcined at $600{ }^{\circ} \mathrm{C}$ for a further 2 hours.

\subsection{Characterisation}

Microscopic images were recorded using a JEOL JEM 210 transmission electron microscope (TEM). Semi-quantitative chemical analysis was performed by energy-dispersive X-ray spectroscopy (EDX) using an Apollo 40 SDD instrument. X-ray diffraction (XRD) was conducted in powder spinning mode at ambient conditions using a Panalytical X'Pert Powder diffractometer with $\mathrm{Cu} \mathrm{K}_{\alpha}$ radiation $(\lambda=0.15406 \mathrm{~nm})$. All powder diffraction patterns were recorded with a step size of 0.052 and step time $200 \mathrm{~s}$, using an X-ray tube operated at $40 \mathrm{kV}$ and $30 \mathrm{~mA}$ with a fixed $1 / 2^{\circ}$ anti-scatter slit. Nitrogen adsorption/desorption measurements were carried out using a Micromeritics ASAP 2020 Surface Analyser at $-196{ }^{\circ} \mathrm{C}$. Samples were degassed under vacuum $\left(\mathrm{p}<10^{-3} \mathrm{~Pa}\right)$ for $3 \mathrm{~h}$ at $300{ }^{\circ} \mathrm{C}$ prior to analysis. BET surface areas of the samples were calculated in the relative pressure range 0.05-0.30. 


\section{Results and Discussion}

Hydroxyapatite (HAP) was synthesised as described in the experimental section and summarised in Figure 1. The reported wet chemical methodology for the first time employs carbon nanorods as a hard approach to synthesising mesoporous HAP. After each step of the procedure, consequent products were characterised for crystallinity and porosity using several techniques. First, SBA-15, mesoporous silica with hexagonal pore morphology, was synthesised using TEOS as a precursor and exploited as a template for carbon nanorod assembly. Nitrogen adsorption isotherms were used to establish surface characteristics, including BET surface area and mesopore volumes, Figure 2. The surface area of SBA-15 was $667.32( \pm 4.91) \mathrm{m}^{2} \mathrm{~g}^{-1}$ with average pore diameter $5.1 \mathrm{~nm}$ (Table 1). Following this, the silica template was impregnated with acidified sucrose solution and after a series of thermal treatments, a carbonisation process occurred to obtain carbon nanorods. TEM images revealed that these carbon nanorods were formed with a hexagonal morphology, as shown in Figure 3A. The surface area of the nanorods was $315.59( \pm 4.60) \mathrm{m}^{2} \mathrm{~g}^{-1}$ with average pore diameter $3.9 \mathrm{~nm}$ (see Table 1).

Next, carbon nanorods were dispersed and used in the precipitation of HAP, employing a wet chemical synthetic route, reported elsewhere[31], followed by template removal, giving porous HAP as a final product. The TEM image shown in Figure 3B shows hexagonal crystals of HAP with repeated structural arrangements, which happen to be columns of calcium ions and oxygen atoms that are located parallel to the hexagonal axis.[19] Subsequently, the XRD pattern of the synthesised HAP is shown in Figure 3C. All major peaks correspond to hexagonal HAP when compared to standard diffraction pattern (JCPDS 09/0432)[31] and shows that there is not any secondary phases observed, such as $\alpha$ - or $\beta$-Tricalcium phosphate ( $\alpha$ - or $\beta$-TCP).[32] EDX analysis was performed to examine the elemental composition of the synthesised product and, based on the results, it is clear that the elemental ratio of materials corresponds to the stoichiometry of HAP (Ca: $37.32 \mathrm{wt} \%$; P: $19.99 \mathrm{wt} \%$; O: $36.13 \mathrm{wt} \%$ ). However, there is also sodium present in an amount of $1.67 \mathrm{wt} \%$ in the obtained powder, which can be explained, because $\mathrm{NaOH}$ was utilised to maintain a stable basic $\mathrm{pH}$ during the synthesis process. Nevertheless, this impurity can be considered as insignificant. BJH pore size distributions show that the HAP contained a mixture of pores; pores with diameter $3.5 \mathrm{~nm}$ are present due to the direct templating with the carbon nanorods while capillary condensation between HAP particles results in a broad distribution of pores with average diameter $18.9 \mathrm{~nm}$ (Figure 3D). What makes this novel approach even more interesting is that the surface area of the 
synthesised HAP is $242.20( \pm 2.27) \mathrm{m}^{2} \mathrm{~g}^{-1}$, having large pores with an average pore diameter of $18.9 \mathrm{~nm}$. The high porosity described herein considerably exceeds that reported by Cheikhi et.al., where surface areas over four times lower have been previously reported.[9] The other synthesis protocol has been published by Chen et.al.[33], where nonionic biodegradable surfactant Tomadol 23-6.5 and petroleum ether were employed as an emulsion system to improve porosity, giving a surface area of $190 \mathrm{~m}^{2} \mathrm{~g}^{-1}$. Amer et.al [34] however, utilised zwitterions surfactant as a template using sol-gel synthetic route assisted by microwave irradiation to synthesise mesoporous nano-HAP and obtained surface area of $87 \mathrm{~m}^{2} \mathrm{~g}^{-1}$. Finally, all the results presented here demonstrate the successful synthesis of single-phase mesoporous HAP via a hard template protocol giving significantly higher porosity to that previously reported (see above). 


\section{Conclusions}

This paper has reported a novel methodology to obtain mesoporous single crystal hydroxyapatite (HAP) using carbon nanorods as a hard-templating approach. The proposed synthetic approach utilised carbon nanorods synthesised using an acidified sucrose solution impregnated onto a silica template (SBA-15). TEM confirmed HAP formation and reveals large pores and characteristic parallel channels that involve calcium ions and oxygen atoms. Hexagonal P63/m crystal arrangements were successfully obtained and the crystallinity of the structure was confirmed by XRD. Moreover, BET analysis determined that the reported HAP possesses a surface area of $242.20( \pm 2.27) \mathrm{m}^{2} \mathrm{~g}^{-1}$ with the average pore diameter $3.5 \mathrm{~nm}$ and $18.9 \mathrm{~nm}$ making it a promising biomaterial for further medical or environmental applications. 


\section{Figure 1.}

Overview of the bespoke synthetic process of HAP using carbon nanorods as a hard template fabrication method.
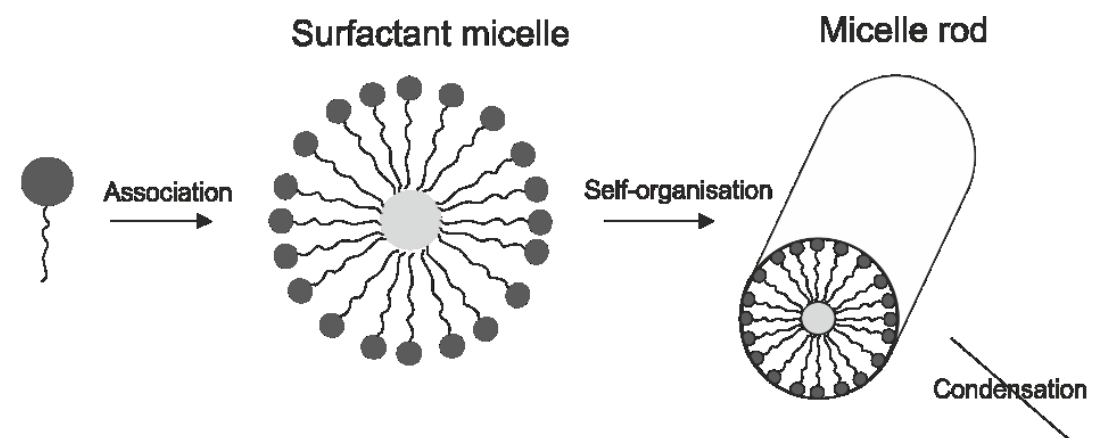

Hexagonal array
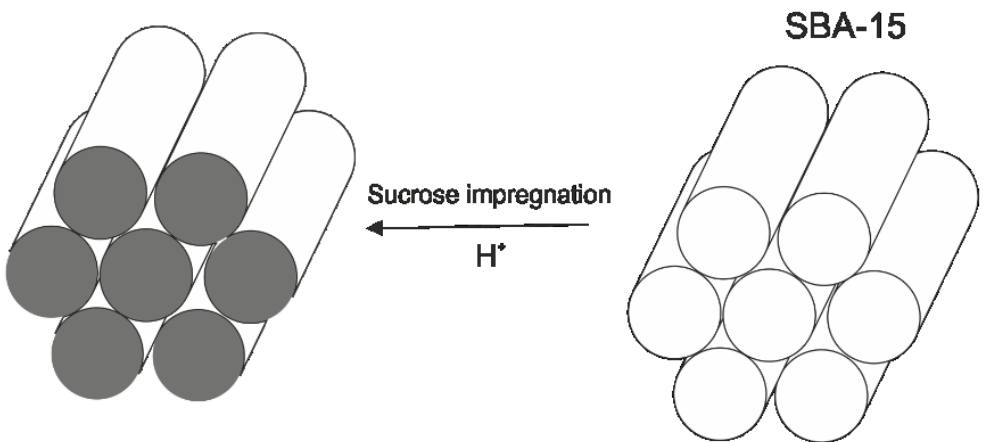

Calcination

in autoclave, $T$,
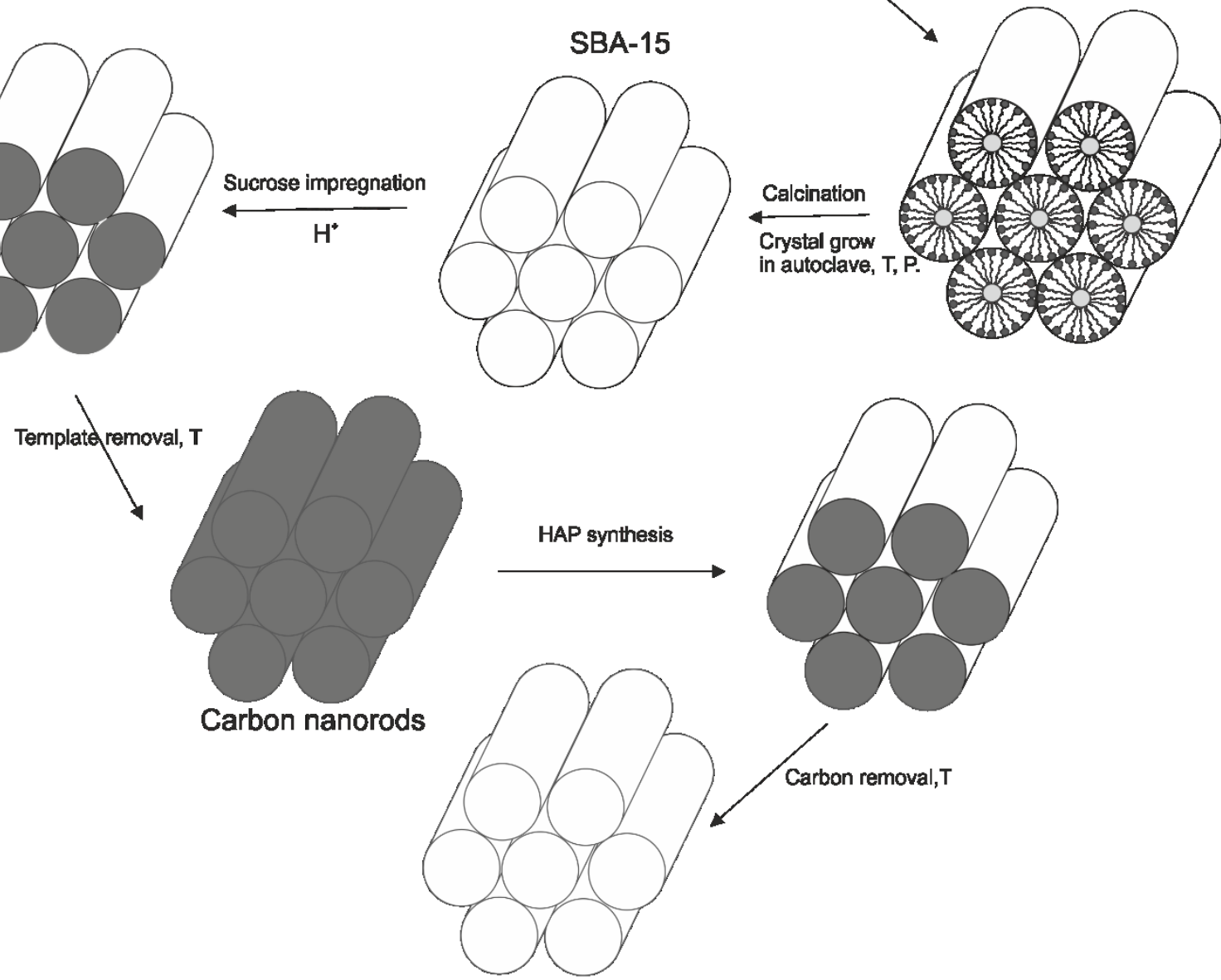

HAP 
Figure 2.

TEM images and nitrogen adsorption isotherm of SBA-15.
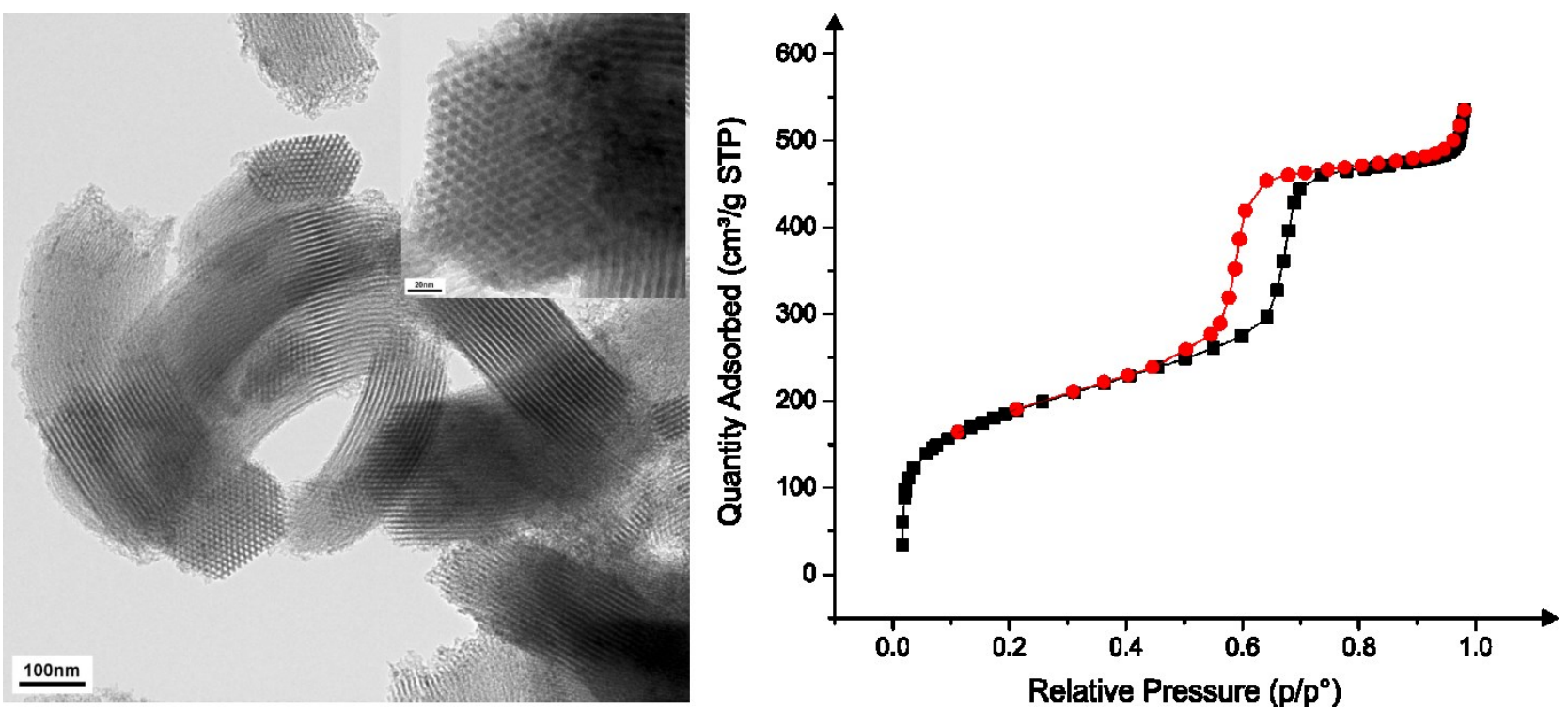


\section{Figure 3.}

TEM images of carbon nanorod templates (A) and fabricated mesoporous HAP (B); XRD pattern of the synthesised HAP (C); BJH pore size distribution (D)
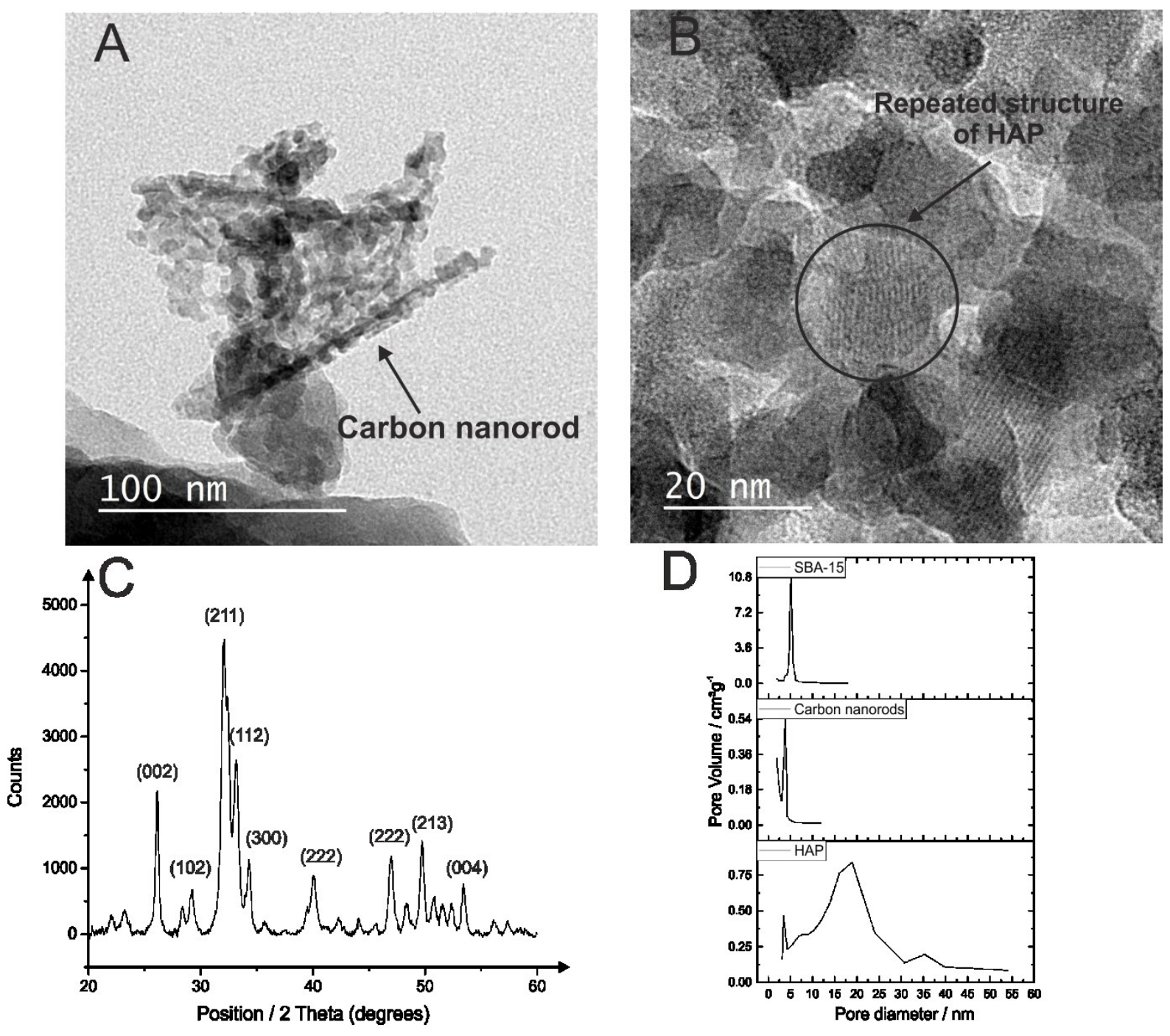
Table 1. Nitrogen adsorption porosimetry data.

\begin{tabular}{cccc} 
Material & $\begin{array}{c}\text { Surface Area } \\
\left(\boldsymbol{m}^{\mathbf{2}} \mathbf{g}^{-1}\right)\end{array}$ & $\begin{array}{c}\text { BJH pore diameter } \\
(\mathbf{n m})\end{array}$ & $\begin{array}{c}\text { Particle diameter } \\
(\mathbf{n m})\end{array}$ \\
\hline SBA-15 & $667.32( \pm 4.91)$ & 5.1 & $\mathrm{ca} .100$ \\
\hline Carbon nanorods & $315.59( \pm 4.61)$ & 3.9 & 4.5 \\
\hline HAP & $242.20( \pm 2.27)$ & $3.5 ; 18.9$ & 14.9 \\
\hline
\end{tabular}




\section{References}

[1] Y.-H. Yang, C.-H. Liu, Y.-H. Liang, F.-H. Lin, K.C.W. Wu, Hollow mesoporous hydroxyapatite nanoparticles (hmHANPs) with enhanced drug loading and $\mathrm{pH}$-responsive release properties for intracellular drug delivery, Journal of Materials Chemistry B 1 (19) (2013) 2447-2450.

[2] J.M. Hughes, Structure and Chemistry of the Apatites and Other Calcium Orthophosphates By J.

C. Elliot (The London Hospital Medical College). Elsevier: Amsterdam. 1994. xii + 389 pp. ISBN 0-44481582-1, Journal of the American Chemical Society 118 (12) (1996) 3072-3072.

[3] M. Gruselle, Apatites: A new family of catalysts in organic synthesis, Journal of Organometallic Chemistry 793 (2015) 93-101.

[4] B. Yan, L.-Z. Tao, Y. Liang, B.-Q. Xu, Sustainable Production of Acrylic Acid: Catalytic Performance of Hydroxyapatites for Gas-Phase Dehydration of Lactic Acid, ACS Catalysis 4 (6) (2014) 1931-1943.

[5] V.C. Ghantani, S.T. Lomate, M.K. Dongare, S.B. Umbarkar, Catalytic dehydration of lactic acid to acrylic acid using calcium hydroxyapatite catalysts, Green Chemistry 15 (5) (2013) 1211-1217.

[6] J.T. Kozlowski, R.J. Davis, Heterogeneous Catalysts for the Guerbet Coupling of Alcohols, ACS Catalysis 3 (7) (2013) 1588-1600.

[7] L. Silvester, J.-F. Lamonier, J. Faye, M. Capron, R.-N. Vannier, C. Lamonier, J.-L. Dubois, J.-L. Couturier, C. Calais, F. Dumeignil, Reactivity of ethanol over hydroxyapatite-based Ca-enriched catalysts with various carbonate contents, Catalysis Science \& Technology 5 (5) (2015) 2994-3006.

[8] T. Tsuchida, T. Yoshioka, S. Sakuma, T. Takeguchi, W. Ueda, Synthesis of Biogasoline from Ethanol over Hydroxyapatite Catalyst, Industrial \& Engineering Chemistry Research 47 (5) (2008) 1443-1452. [9] N. Cheikhi, M. Kacimi, M. Rouimi, M. Ziyad, L.F. Liotta, G. Pantaleo, G. Deganello, Direct synthesis of methyl isobutyl ketone in gas-phase reaction over palladium-loaded hydroxyapatite, Journal of Catalysis 232 (2) (2005) 257-267.

[10] D. Miao, A. Goldbach, H. Xu, Platinum/Apatite Water-Gas Shift Catalysts, ACS Catalysis 6 (2) (2016) 775-783.

[11] S. Sugiyama, T. Minami, H. Hayashi, M. Tanaka, J.B. Moffat, Surface and Bulk Properties of Stoichiometric and Nonstoichiometric Strontium Hydroxyapatite and the Oxidation of Methane, Journal of Solid State Chemistry 126 (2) (1996) 242-252.

[12] C. Boucetta, M. Kacimi, A. Ensuque, J.-Y. Piquemal, F. Bozon-Verduraz, M. Ziyad, Oxidative dehydrogenation of propane over chromium-loaded calcium-hydroxyapatite, Applied Catalysis A: General 356 (2) (2009) 201-210.

[13] J.H. Park, D.-W. Lee, S.-W. Im, Y.H. Lee, D.-J. Suh, K.-W. Jun, K.-Y. Lee, Oxidative coupling of methane using non-stoichiometric lead hydroxyapatite catalyst mixtures, Fuel 94 (2012) 433-439.

[14] S.C. Oh, Y. Wu, D.T. Tran, I.C. Lee, Y. Lei, D. Liu, Influences of cation and anion substitutions on oxidative coupling of methane over hydroxyapatite catalysts, Fuel 167 (2016) 208-217.

[15] N. Takarroumt, M. Kacimi, F. Bozon-Verduraz, L.F. Liotta, M. Ziyad, Characterization and performance of the bifunctional platinum-loaded calcium-hydroxyapatite in the one-step synthesis of methyl isobutyl ketone, Journal of Molecular Catalysis A: Chemical 377 (2013) 42-50.

[16] D. Chlala, M. Labaki, J.-M. Giraudon, O. Gardoll, A. Denicourt-Nowicki, A. Roucoux, J.-F. Lamonier, Toluene total oxidation over Pd and Au nanoparticles supported on hydroxyapatite, Comptes Rendus Chimie 19 (4) (2016) 525-537.

[17] Z. Qu, Y. Sun, D. Chen, Y. Wang, Possible sites of copper located on hydroxyapatite structure and the identification of active sites for formaldehyde oxidation, Journal of Molecular Catalysis A:

Chemical 393 (2014) 182-190.

[18] Z. Boukha, J. González-Prior, B.d. Rivas, J.R. González-Velasco, R. López-Fonseca, J.I. GutiérrezOrtiz, Synthesis, characterisation and behaviour of $\mathrm{Co} / \mathrm{hydroxyapatite}$ catalysts in the oxidation of 1,2-dichloroethane, Applied Catalysis B: Environmental 190 (2016) 125-136.

[19] Z. Opre, J.D. Grunwaldt, M. Maciejewski, D. Ferri, T. Mallat, A. Baiker, Promoted Ruhydroxyapatite: designed structure for the fast and highly selective oxidation of alcohols with oxygen, Journal of Catalysis 230 (2) (2005) 406-419. 
[20] Z. Opre, D. Ferri, F. Krumeich, T. Mallat, A. Baiker, Aerobic oxidation of alcohols by organically modified ruthenium hydroxyapatite, Journal of Catalysis 241 (2) (2006) 287-295.

[21] K. Zhao, B. Qiao, J. Wang, Y. Zhang, T. Zhang, A highly active and sintering-resistant Au/FeOxhydroxyapatite catalyst for CO oxidation, Chemical Communications 47 (6) (2011) 1779-1781.

[22] J.H. Jun, T.-J. Lee, T.H. Lim, S.-W. Nam, S.-A. Hong, K.J. Yoon, Nickel-calcium

phosphate/hydroxyapatite catalysts for partial oxidation of methane to syngas: characterization and activation, Journal of Catalysis 221 (1) (2004) 178-190.

[23] J.H. Jun, T.H. Lim, S.-W. Nam, S.-A. Hong, K.J. Yoon, Mechanism of partial oxidation of methane over a nickel-calcium hydroxyapatite catalyst, Applied Catalysis A: General 312 (2006) 27-34.

[24] Z. Boukha, M. Kacimi, M. Ziyad, A. Ensuque, F. Bozon-Verduraz, Comparative study of catalytic activity of Pd loaded hydroxyapatite and fluoroapatite in butan-2-ol conversion and methane oxidation, Journal of Molecular Catalysis A: Chemical 270 (1-2) (2007) 205-213.

[25] K.H. Kim, S.Y. Lee, K.J. Yoon, Effects of ceria in $\mathrm{CO} 2$ reforming of methane over Ni/calcium hydroxyapatite, Korean Journal of Chemical Engineering 23 (3) (2006) 356-361.

[26] M. Šupová, Substituted hydroxyapatites for biomedical applications: A review, Ceramics International 41 (8) (2015) 9203-9231.

[27] D. Bellucci, A. Sola, M. Gazzarri, F. Chiellini, V. Cannillo, A new hydroxyapatite-based biocomposite for bone replacement, Materials Science and Engineering: C 33 (3) (2013) 1091-1101.

[28] S.V. Dorozhkin, Bioceramics of calcium orthophosphates, Biomaterials 31 (7) (2010) 1465-1485. [29] H.P. Wiesmann, U. Plate, K. Zierold, H.J. Höhling, Potassium is involved in apatite biomineralization, Journal of Dental Research 77 (8) (1998) 1654-1657.

[30] B.S. Moonga, D.W. Dempster, Zinc is a potent inhibitor of osteoclastic bone resorption in vitro, Journal of Bone and Mineral Research 10 (3) (1995) 453-457.

[31] J. Kamieniak, E. Bernalte, C. Foster, A. Doyle, P. Kelly, C. Banks, High Yield Synthesis of Hydroxyapatite (HAP) and Palladium Doped HAP via a Wet Chemical Synthetic Route, Catalysts 6 (8) (2016) 119.

[32] P. Kamalanathan, S. Ramesh, L.T. Bang, A. Niakan, C.Y. Tan, J. Purbolaksono, H. Chandran, W.D. Teng, Synthesis and sintering of hydroxyapatite derived from eggshells as a calcium precursor, Ceramics International 40 (10, Part B) (2014) 16349-16359.

[33] C.-W. Chen, R.E. Riman, K.S. TenHuisen, K. Brown, Mechanochemical-hydrothermal synthesis of hydroxyapatite from nonionic surfactant emulsion precursors, Journal of Crystal Growth 270 (3-4) (2004) 615-623.

[34] W. Amer, K. Abdelouahdi, H.R. Ramananarivo, M. Zahouily, A. Fihri, Y. Coppel, R.S. Varma, A. Solhy, Synthesis of mesoporous nano-hydroxyapatite by using zwitterions surfactant, Materials Letters 107 (2013) 189-193. 